\title{
TENDÊNCIAS ECOLÓGICAS NA ANATOMIA DA MADEIRA DE ESPÉCIES DA Comunidade arbórea da Reserva Biológica de Poço das Antas, Rio De JaNeiro, Brasil
}

\author{
Claudia Franca Barros ${ }^{1}$, Micheline Leite Marcon-Ferreira ${ }^{1,5}$, \\ Cátia Henriques Callado ${ }^{2,6}$, Helena Regina Pinto Lima ${ }^{3}$, \\ Maura da Cunha ${ }^{4,7}$, Osnir Marquete ${ }^{1} \&$ Cecília Gonçalves Costa ${ }^{1,7}$
}

\section{Resumo}

(Tendências ecológicas na anatomia da madeira de espécies da comunidade arbórea da Reserva Biológica de Poço das Antas, Rio de Janeiro, Brasil) O trabalho propõe a utilização dos caracteres anatômicos da madeira na interpretação da estrutura da comunidade arbórea da Reserva Biológica de Poço das Antas, RJ, Brasil ( $22^{\circ} 30^{\prime}$ e $22^{\circ} 33^{\prime} \mathrm{S}$ e $42^{\circ} 15^{\prime}$ e $\left.42^{\circ} 19^{\prime} \mathrm{W}\right)$. Foram analisadas 26 espécies de 14 famílias, totalizando 72 espécimens. A alta incidência de características anatômicas comuns - camadas de crescimento distintas, porosidade difusa, placas de perfuração simples, fibras de paredes delgadas a espessas, raios com freqüência de 4 a 12/mm', com 1-3 células de largura, - foi corroborada pelas análises estatísticas, o que sugere a ocorrência de um padrão anatômico. Os resultados descritos se enquadram nas tendências ecológicas para espécies de planícies tropicais, que se caracterizam por uma menor freqüência de elementos de vaso mais largos e com placas de perfuração simples. Tais caracteres propiciam o transporte de grandes volumes de água por unidade de tempo e área transversal da madeira.

Palavras-chave: Floresta Atlântica, anatomia ecológica, anatomia da madeira.

\section{Abstract}

(Ecological trends in wood anatomy of tree species at Reserva Biológica de Poço das Antas, Rio de Janeiro, Brazil) Wood anatomy features were used to interpretate the structure of the tree community at the

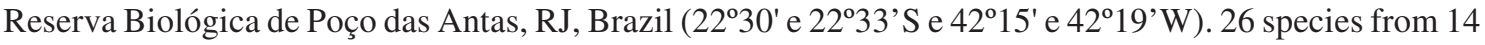
families and 72 specimens were analysed. The high incidence of anatomical features observed in most of species, as growth rings, difuse porosity, simple perfuration plates, thick-to-thin fibres, 1-3 rays wide and 4 to $12 / \mathrm{mm}$ ', statistically suggested there was an anatomical pattern. Results were in accordance with ecological trends for tropical lowland species, characterized by simple perforarion plates, low frequency and widening of vessels. These features allow the conduction of large volumes of water per unit time and transectional area of wood.

Key words: Atlantic rain forest, ecological anatomy, wood anatomy.

\section{INTRODUÇÃO}

Os padrões de diversidade e suas variações nos diferentes habitats constituem os principais temas focalizados em estudos de comunidades biológicas (Magurran 1988;
Nunes-Freitas 2004). Em comunidades vegetais tal diversidade é geralmente expressa pela contagem geral do número de espécies, pela abundância relativa e composição das espécies ou pela variação

\footnotetext{
Artigo recebido em 02/2005. Aceito para publicação em 05/2006.

${ }^{1}$ Instituto de Pesquisas Jardim Botânico do Rio de Janeiro, Programa Mata Atlantica, Laboratório de Botânica Estrutural. Rua Pacheco Leão, 915, 22460-030, Rio de Janeiro, RJ, Brasil. cbarros@jbrj.gov.br

${ }^{2}$ Universidade do Estado do Rio de Janeiro, Departamento de Biologia Vegetal, Laboratório de Anatomia Vegetal.

${ }^{3}$ Universidade Federal Rural do Rio de Janeiro, Instituto de Biologia, Departamento de Botânica.

${ }^{4}$ Universidade Estadual do Norte Fluminense, Centro de Biociências e Biotecnologia, Laboratório de Biologia Celular e Tecidual, Setor de Citologia Vegetal.

${ }^{5}$ Bolsista Fundação Botânica Margaret Mee.

${ }^{6}$ Bolsista PROCIÊNCIA - UERJ/FAPERJ.

${ }^{7}$ Bolsista Produtividade CNPq.

Apoio Financeiro: Petrobras, CNPq, FENORTE/TECNORTE.
} 
dessa composição ao longo de um gradiente ambiental (Guedes-Bruni 1998; Lima 2000; Nunes-Freitas 2004). Esses parâmetros são obtidos por meio de inventários florísticos e fitossociológicos, que fornecem informações básicas subsidiando os estudos botânicos subsequientes (Guedes-Bruni et al. 2002; Vuono 2002).

A estrutura anatômica das madeiras também pode refletir tal diversidade e a variação entre diferentes habitats. Carlquist (2001) sugere duas abordagens diferentes no que diz respeito aos métodos utilizados para expressar a correlação ecologia-anatomia. Uma é fundamentada em grupos taxonômicos, e visa a análise comparativa de espécies de um mesmo gênero em um gradiente ecológico. A outra envolve a comparação de pequenas áreas ou flórulas, visando o reconhecimento de caracteres anatômicos comuns a uma dada formação vegetal, independente dos grupos taxonômicos analisados (p.ex. Carlquist 1977; Barajas-Morales 1985; Noshiro et al. 1995). Tais características são consideradas importantes para o desempenho das funções do xilema em condições ambientais diversas e expressam as tendências ecológicas em gradientes latitudinais e altitudinais em diferentes macro e mesoclimas (p. ex. Baas et al. 1983; Dickison 1989; Woodcock et al. 2000). Wheeler \& Baas (1991) utilizando o modelo proposto por Dickison (1989) e a literatura disponível, relacionaram as tendências ecológicas gerais para hábitats xéricos, montanos e tropicais. Os resultados dessas investigações têm grande relevância para a inferência de climas de eras passadas, sendo utilizados também em estudos filogéneticos (Wheeler \& Baas 1991; Wiemann et al. 1998). Trabalhos focalizando as características anatômicas em uma abordagem de flórula em biomas brasileiros são ainda escassos, destacando-se Callado et al. (1997) que estudaram 14 espécies de um remanescente de Floresta Atlântica de Macaé de Cima, Nova Fribrurgo, Rio Janeiro.
O presente trabalho visa colaborar para o melhor conhecimento de um remanescente de Floresta Ombrófila Densa das terras baixas no estado do Rio de Janeiro, a partir de uma abordagem de flórula aplicada à anatomia. Propõe-se utilizar as características anatômicas do lenho na interpretação da estrutura da comunidade arbórea, visando responder às seguintes questões:

- Existe um padrão anatômico característico para as espécies analisadas?

- As características anatômicas analisadas expressam tendências ecológicas típicas de regiões tropicais de planície, de acordo com o proposto por Dickison (1989) e modificado por Wheeler \& Baas (1991)?

\section{Material e Métodos}

As coletas foram efetuadas na Reserva Biológica de Poço das Antas (22³0' e $22^{\circ} 33^{\prime} \mathrm{S}$ e $42^{\circ} 15^{\prime}$ e $\left.42^{\circ} 19^{\prime} \mathrm{W}\right)$, município de Silva Jardim, um remanescente de Floresta Atlântica no estado do Rio de Janeiro, caracterizado por vegetação do tipo Floresta Ombrófila Densa de terras baixas (Velloso et al 1992; Guedes-Bruni 1998). A topografia do local é predominantemente de planície, com morros e morrotes de perfis arredondados, cuja altura varia entre 30 a 200 msm, separados por várzeas alagadiças, de fundo achatado. O clima é do tipo úmido e megatérmico, com pluviosidade média anual de $2.260 \mathrm{~mm}$ e temperatura média de $24,5^{\circ} \mathrm{C}$. O solo é pouco espesso, arenosoargiloso e fortemente ácido, tanto nas várzeas alagadiças como nas áreas livres de inundação (Guedes-Bruni 1998).

Foram estudadas 26 espécies pertencentes a 14 famílias botânicas, totalizando 72 espécimes inventariados (Tab. 1). As espécies foram selecionadas com base em estudos prévios de cunho florístico e fitossociológico (Guedes-Bruni 1998) e englobam os táxons de maior representatividade numérica, espécies raras e aquelas indicadas para revegetação de áreas degradadas na região (Guedes-Bruni 
1998). As coletas foram efetuadas em sítios da Reserva, incluindo fragmentos periódica ou permanentemente alagáveis ao nível do mar.

Para a coleta do lenho foram selecionados espécimes de tronco cilíndrico, reto e sem bifurcação ou defeito aparente, com diâmetro à altura do peito (DAP) igual ou superior a 12 $\mathrm{cm}$. As amostras foram retiradas a $1,30 \mathrm{~m}$ do solo por método não destrutivo (Barros et al. 1997, 2001).

O material foi processado no Laboratório de Botânica Estrutural do Instituto de Pesquisas Jardim Botânico do Rio de Janeiro, conforme as Normas de Procedimento em Estudos de Anatomia da Madeira (Coradin \& Muñiz 1991). As seções foram coradas por safranina hidroalcoólica a $50 \%$ (Sass 1958) ou pela mistura azul de astra e safranina (Bukatsch 1972) e montadas em Permount. As contagens e mensurações dos elementos celulares obedeceram às normas do IAWA Committee (1989) e Coradin \& Muñiz (1991). A aferição do agrupamento de vasos foi obtida segundo Carlquist (1984). Esses procedimentos (mensurações, contagens e aferições) foram realizados com auxílio da ocular micrométrica, acoplada ao microscópio Olympus ou por meio de uma câmara de vídeo Sony acoplada ao mesmo microscópio e ao computador, utilizando o software Image Pro Plus versão 4.0 para Windows.

As análises estatísticas foram efetuadas com a ajuda do software Statistic 6.0. O teste de Shapiro-Wilk W foi utilizado para testar a normalidade das amostras (Zar 1996). Para verificar a formação de grupos distintos foi realizada uma análise de agrupamento, baseada numa matriz de distância de Manhattan (Sneath \& Sokal 1973) para dados binários, usando os caracteres qualitativos relacionados na Tabela 1. A análise dos componentes principais foi utilizada para ordenar as espécies e os caracteres anatômicos quantitativos e qualitativos, evidenciando os fatores de maior variância (Ludwig \& Reynolds 1988). 
Tabela 1 - Listagem das famílias e espécies coletadas, números de registro na Xiloteca do Jardim

\begin{tabular}{|c|c|c|c|c|c|c|c|c|c|c|}
\hline Família & 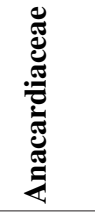 & 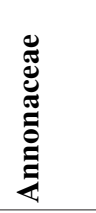 & 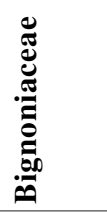 & & & 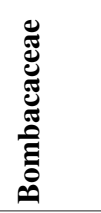 & & 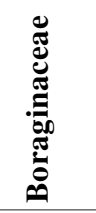 & 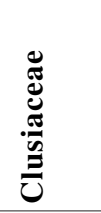 & \\
\hline Espécie & 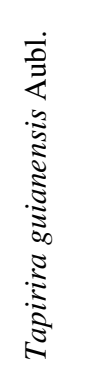 & 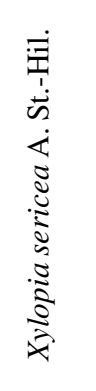 & 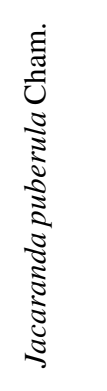 & 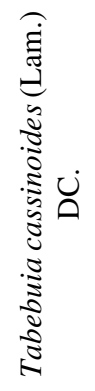 & 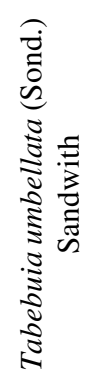 & 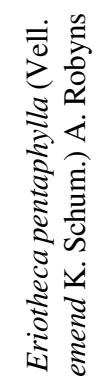 & 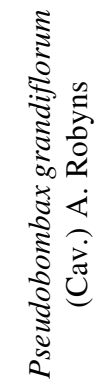 & 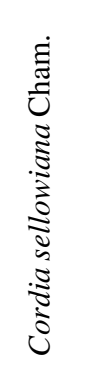 & 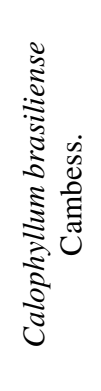 & 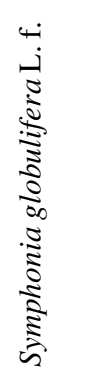 \\
\hline $\mathrm{RBw}$ & $\begin{array}{l}7524, \\
7526, \\
7527\end{array}$ & $\begin{array}{l}7336 \\
7338 \\
7355\end{array}$ & $\begin{array}{l}7328, \\
7335, \\
7363 \\
7449\end{array}$ & $\begin{array}{l}7329 \\
7333, \\
7477, \\
7478\end{array}$ & $\begin{array}{l}7475 \\
7476\end{array}$ & $\begin{array}{l}7455 \\
7461 \\
7462\end{array}$ & $\begin{array}{l}7331 \\
7340 \\
7473 \\
7474\end{array}$ & $\begin{array}{l}7326 \\
7356\end{array}$ & $\begin{array}{l}7366 \\
7368\end{array}$ & $\begin{array}{l}7341, \\
7342, \\
7360\end{array}$ \\
\hline Camadas de crescimento & + & + & + & + & + & + & + & + & + & \\
\hline $\begin{array}{l}\text { Porosidade difusa } \\
\text { Vasos exclusivamente solitários } \\
<5 \text { vasos } / \mathrm{mm}^{2}\end{array}$ & + & + & + & + & + & + & + & + & $\begin{array}{l}+ \\
+\end{array}$ & + \\
\hline $\begin{array}{l}5-20 \text { vasos } / \mathrm{mm}^{2} \\
40-100 \text { vasos } / \mathrm{mm}^{2}\end{array}$ & + & + & + & + & + & & & + & + & + \\
\hline Comprimento do vaso $<350 \mu \mathrm{m}$ & & & & & + & & & + & & \\
\hline $\begin{array}{l}\text { Comprimento do vaso } \\
\text { entre } 350 \text { a } 800 \mu \mathrm{m} \\
\text { Comprimento do vaso }>800 \mu \mathrm{m}\end{array}$ & + & + & + & + & & + & + & & + & + \\
\hline $\begin{array}{l}\text { Diâmetro tangencial do } \\
\text { vaso }<50 \mu \mathrm{m}\end{array}$ & & & + & & & + & & & & \\
\hline $\begin{array}{l}\text { Diâmetro tangencial do vaso } \\
50 \text { a } 100 \mu \mathrm{m}\end{array}$ & & & & + & + & & & & & \\
\hline $\begin{array}{l}\text { Diâmetro tangencial do vaso } \\
100 \text { a } 200 \mu \mathrm{m}\end{array}$ & + & + & & & & & & + & + & + \\
\hline $\begin{array}{l}\text { Diâmetro tangencial do vaso } \\
>200 \mu \mathrm{m}\end{array}$ & & & & & & & + & & & \\
\hline Placa de perfuração simples & + & + & + & + & + & + & + & + & + & + \\
\hline $\begin{array}{l}\text { Placa de perfuração } \\
\text { escalarifome }<10 \text { barras }\end{array}$ & + & & & & & & & & & \\
\hline $\begin{array}{l}\text { Placa de perfuração } \\
\text { escalarifome }>10 \text { barras }\end{array}$ & & & & & & & & & & \\
\hline Placa de perfuração radiada & & & & & & & & & & \\
\hline $\begin{array}{l}\text { Placa de perfuração } \\
\text { foraminado-reticulada }\end{array}$ & & & & & & & & & & \\
\hline Pontoações intervasculares opostas & & & & & & & & & & \\
\hline $\begin{array}{l}\text { Pontoações intervasculares alternas } \\
\text { Pontoações intervasculares } \\
\text { diminutas }(<4 \mu \mathrm{m})\end{array}$ & + & + & + & $\begin{array}{l}+ \\
+\end{array}$ & + & + & + & + & & + \\
\hline $\begin{array}{l}\text { Pontoações intervasculares } \\
\text { pequenas }(4 \text { a } 7 \mu \mathrm{m})\end{array}$ & & + & & & & & & & & \\
\hline
\end{tabular}




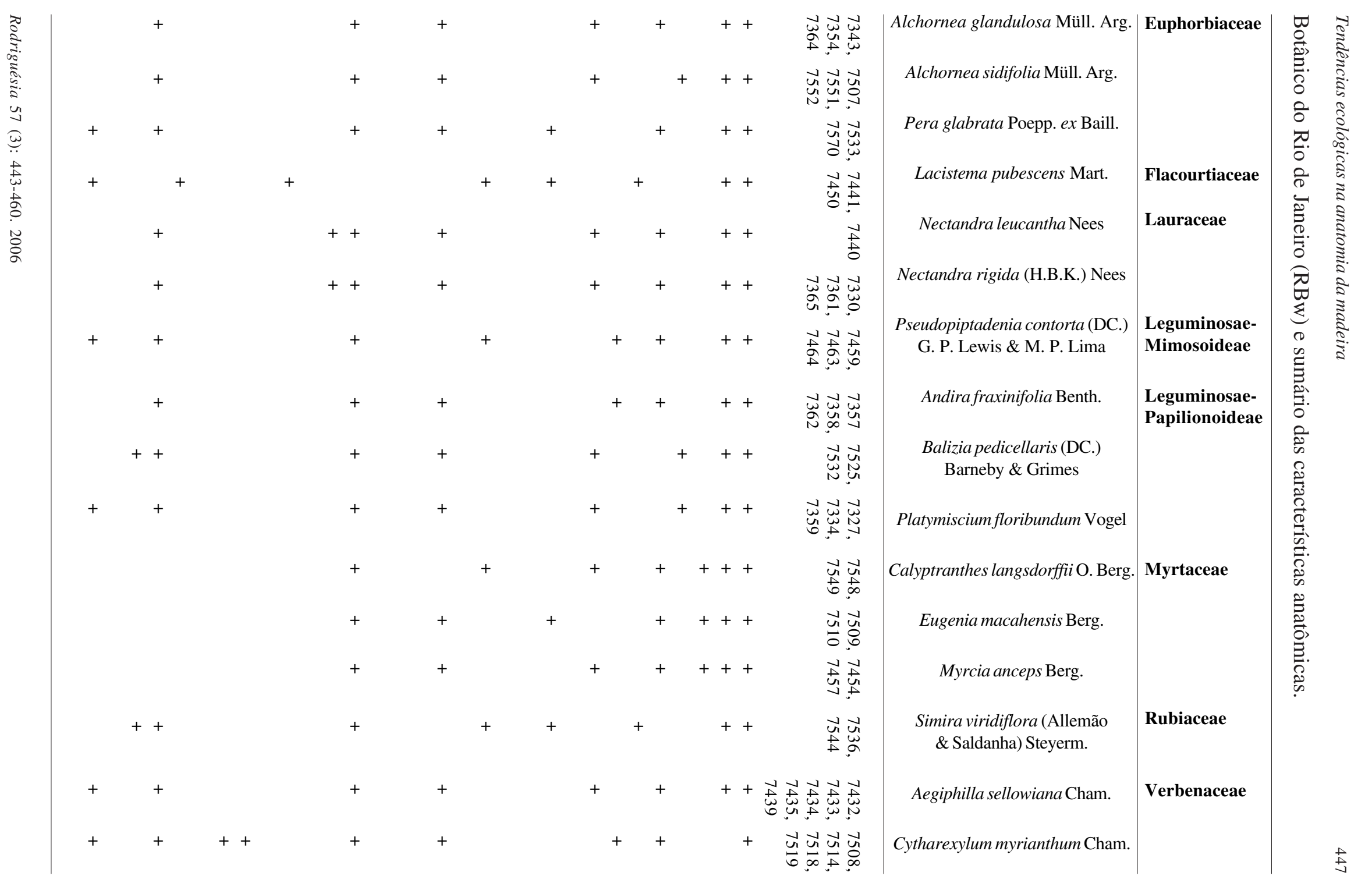




\begin{tabular}{|c|c|c|c|c|c|c|}
\hline Família & 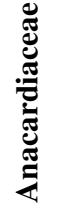 & 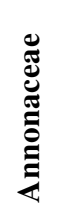 & 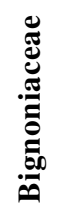 & 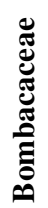 & 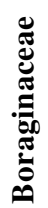 & 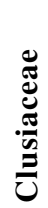 \\
\hline
\end{tabular}

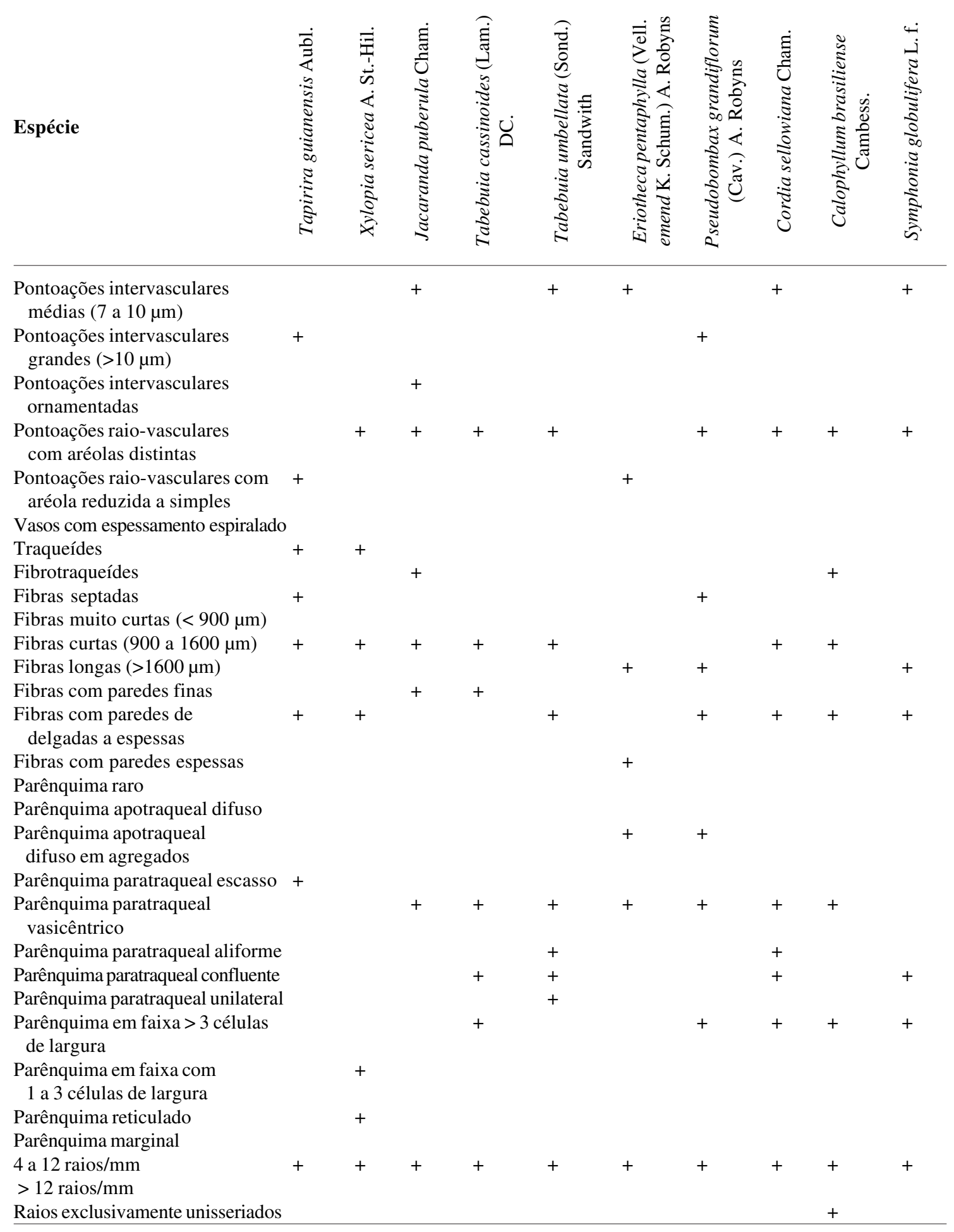



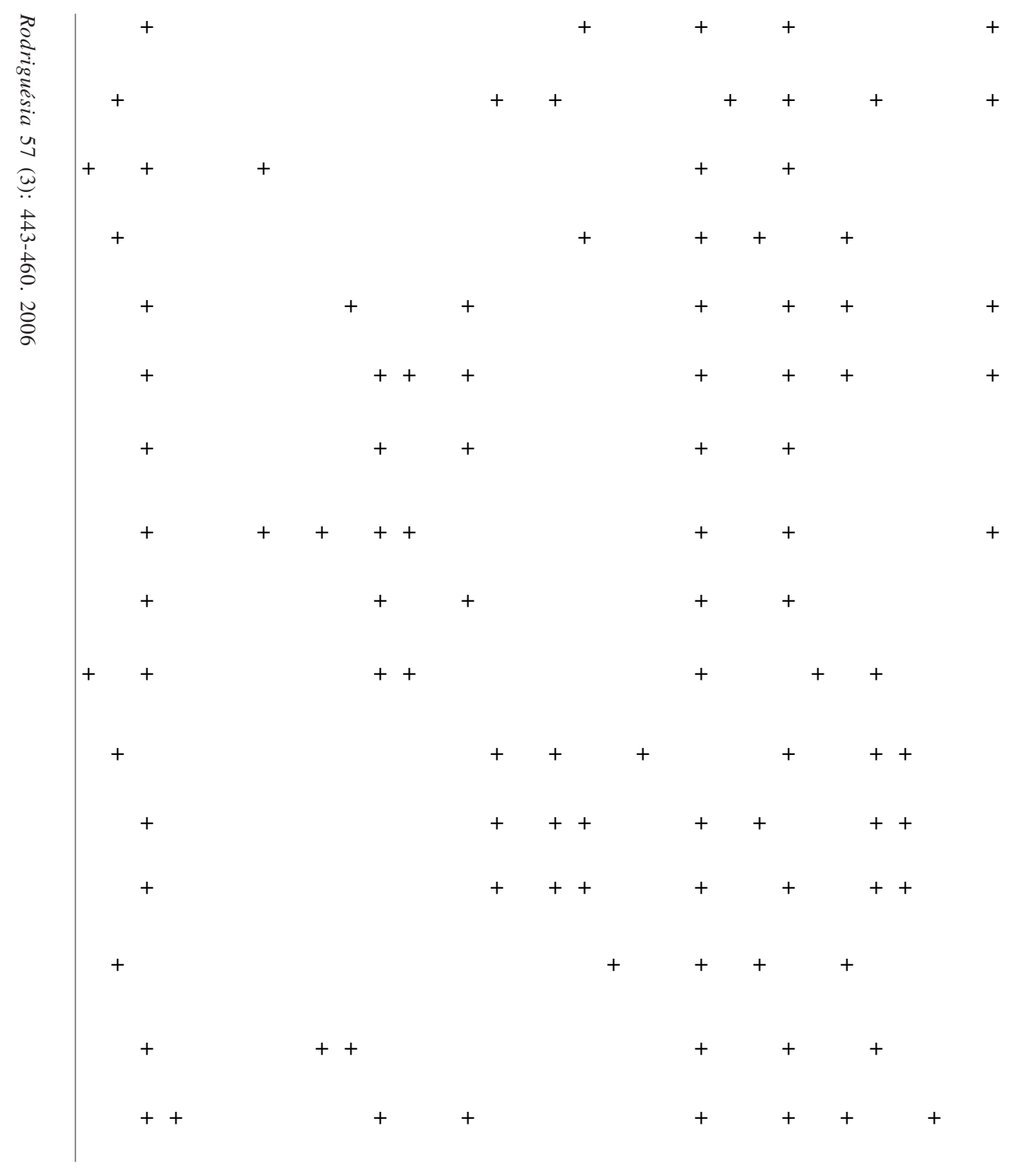

\begin{tabular}{|c|c|}
\hline Alchornea glandulosa Müll. Arg. & Euphorbiaceae \\
\hline Alchornea sidifolia Müll. Arg. & \\
\hline Pera glabrata Poepp. ex Baill. & \\
\hline Lacistema pubescens Mart. & Flacourtiaceae \\
\hline Nectandra leucantha Nees & Lauraceae \\
\hline Nectandra rigida (H.B.K.) Nees & \\
\hline Pseudopiptadenia contorta (DC.) & Leguminosae- \\
\hline G. P. Lewis \& M. P. Lima & Mimosoideae \\
\hline Andira fraxinifolia Benth. & $\begin{array}{l}\text { Leguminosae- } \\
\text { Papilionoideae }\end{array}$ \\
\hline $\begin{array}{c}\text { Balizia pedicellaris (DC.) } \\
\text { Barneby \& Grimes }\end{array}$ & \\
\hline Platymiscium floribundum Vogel & \\
\hline Calyptranthes langsdorffii O. Berg. & Myrtaceae \\
\hline Eugenia macahensis Berg. & \\
\hline Myrcia anceps Berg. & \\
\hline $\begin{array}{l}\text { Simira viridiflora (Allemão } \\
\text { \& Saldanha) Steyerm. }\end{array}$ & Rubiaceae \\
\hline Aegiphilla sellowiana Cham. & Verbenaceae \\
\hline Cytharexylum myrianthum Cham. & \\
\hline
\end{tabular}




Família

\begin{tabular}{|c|c|c|c|c|c|c|c|c|c|c|}
\hline Espécie & 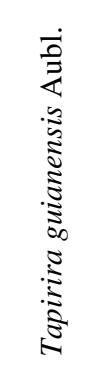 & 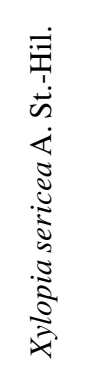 & 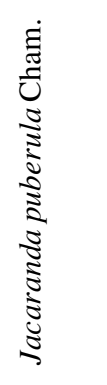 & 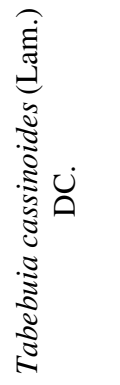 & 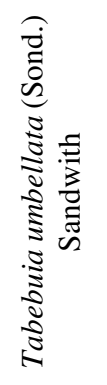 & 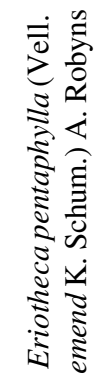 & 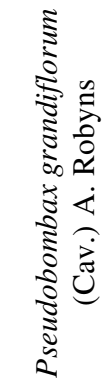 & 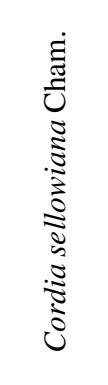 & 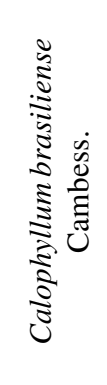 & 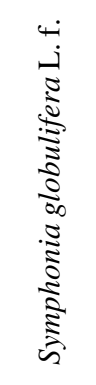 \\
\hline Raios de 1 a 3 células de largura & + & + & + & + & + & + & + & + & & + \\
\hline $\begin{array}{l}\text { Raios }>4 \text { células de largura } \\
\text { Raios }>1 \mathrm{~mm} \text { de altura }\end{array}$ & & + & & & + & + & + & + & & \\
\hline Raios agregados & + & + & & & & & & + & & + \\
\hline $\begin{array}{l}\text { Raios apenas com células } \\
\text { procumbentes }\end{array}$ & & + & & + & + & & & & & + \\
\hline $\begin{array}{l}\text { Raios apenas com células } \\
\text { quadradas e/ou eretas }\end{array}$ & & & & & & & & & & \\
\hline $\begin{array}{l}\text { Raios com procumbentes no } \\
\text { corpo e } 1 \text { fileira de ereta e/ou } \\
\text { quadradas nas margens }\end{array}$ & + & & + & & & + & + & + & + & + \\
\hline $\begin{array}{l}\text { Raios com procumbentes no } \\
\text { corpo e } 2 \text { a } 4 \text { fileiras de ereta } \\
\text { e/ou quadradas nas margens }\end{array}$ & + & & + & & & + & & & & \\
\hline $\begin{array}{l}\text { Raios com procumbentes, } \\
\text { quadradas e eretas misturadas }\end{array}$ & & & & & & & & & & \\
\hline $\begin{array}{l}\text { Parenquima axial e/ou vasos } \\
\text { estrafificados }\end{array}$ & & & & & + & & + & & & \\
\hline $\begin{array}{l}\text { Raios e/ou elementos axiais } \\
\text { irregularmente estratificado }\end{array}$ & & & & & + & & & & & \\
\hline Cristais & + & & & & & & & & + & + \\
\hline Índice de grupamento dos vasos & 1,65 & 1,70 & 1,50 & 1,70 & 1,20 & 2,30 & 2,30 & 1,50 & 1,00 & 1,68 \\
\hline Espessura da parede dos vasos & 3,35 & 3,82 & 3,72 & 4,00 & 4,49 & 4,82 & 5,24 & 4,35 & 3,85 & 4,01 \\
\hline Vasos $/ \mathrm{mm}^{2}$ & 10 & 8 & 15 & 5 & 19 & 3 & 3 & 6 & 7 & 5 \\
\hline $\begin{array}{l}\text { Comprimento dos elementos } \\
\text { de vaso }\end{array}$ & 733,15 & 595,15 & 433,98 & 435,43 & 202,29 & 551,07 & 450,19 & 290,16 & 663,07 & 622,07 \\
\hline $\begin{array}{l}\text { Diâmetro tangencial dos } \\
\text { elementos de vaso }\end{array}$ & 104,69 & 105,46 & 22,69 & 84,63 & 79,02 & 36,22 & 213,74 & 135,17 & 179,93 & 181,39 \\
\hline Comprimento de fibra & 1139,04 & 1174,19 & 1028,36 & 1054,00 & 1188,46 & 2005,00 & 2322,37 & 1030,83 & 1119,11 & 1701,00 \\
\hline
\end{tabular}

\begin{tabular}{lllllllllll} 
Espessura da parede das fibras & 5,41 & 4,09 & 2,11 & 4,00 & 4,00 & 7,55 & 3,99 & 3,66 & 4,3 & 8,79 \\
\hline
\end{tabular} 


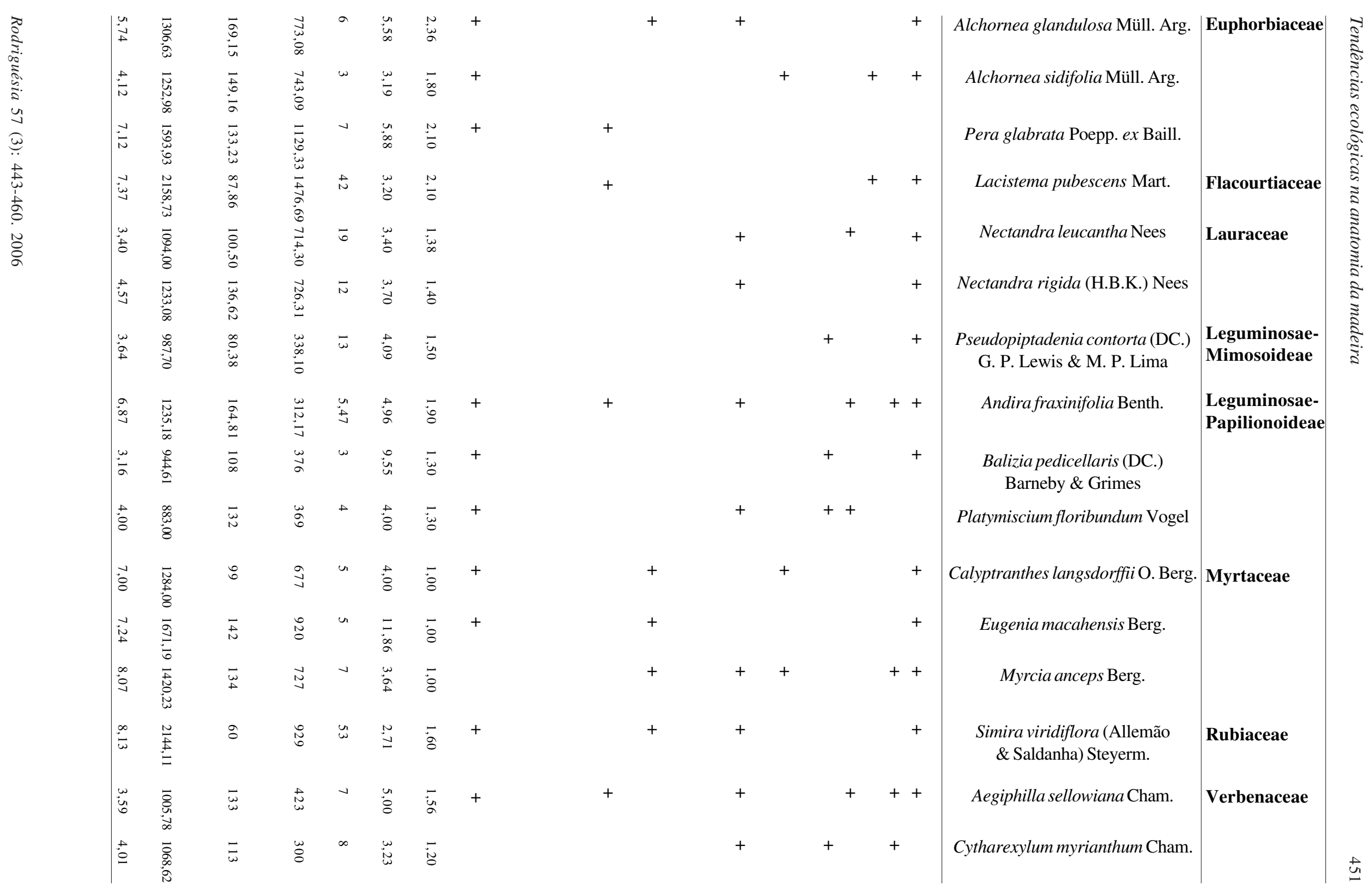




\section{Resultados}

A análise anatômica do material selecionado revelou elevada ocorrência de camadas de crescimento distintas, porosidade difusa, placas de perfuração simples, fibras com paredes delgadas a espessas, maior frequiência de parênquima do tipo paratraqueal em diferentes arranjos e raios com frequiência de 4 a 12/mm', com 1-3 células de largura (Tabs. 1 e 2; Figs. 1-10).

A análise de agrupamento (Fig. 11) demonstra que embora as espécies possam ser segregadas por seus caracteres anatômicos, a maioria não se agrupa por família, com exceção da família Lauraceae cujas espécies mantiveram-se próximas. As demais famílias apresentaram um comportamento diverso, exemplificado pelas espécies de Euphorbiaceae: enquanto Alchornea glandulosa e A. sidifolia mantiveram-se agrupadas, Pera glabrata ficou bastante separada das demais. O dendrograma (Fig. 11) permite verificar ainda, que o representante da família Flacourtiaceae, Lacistema pubescens, destacou-se das demais por ser a única espécie que apresenta elementos de vaso com placas de perfuração escalariforme com mais de 10 barras, e pontoações intervasculares opostas.

A análise do componente principal (PCA) evidenciou que as características anatômicas variam dentro de fatores que, juntos, explicam $66 \%$ da variância total (Fig. 12). O eixo 1 responde por $45 \%$ da variância total e é influenciado fortemente pela ocorrência de placas de perfuração simples e placas de perfuração escalariforme com mais de 10 barras e pela freqüência dos elementos de vaso. O eixo 2 responde por $21 \%$ da variação total e é influenciado pela presença de placas de perfuração escalariforme com menos de 10 barras. Existe uma forte correlação positiva entre a ocorrência de placas de perfuração escalariforme com mais de 10 barras e pontoações intervasculares opostas que, por sua vez, estão negativamente correlacionadas com a presença de placas de perfuração simples. O eixo 1 separa Lacistema pubescens (Flacourtiaceae) pela alta frequiência de vasos associada à ocorrência de placas de perfuração escalariforme com mais de 10 barras, confirmando os resultados da análise de agrupamento. Simira viridiflora (Rubiaceae) se destaca pela combinação de placas de perfuração simples e elevada freqüência de vasos. O eixo 2 separa as espécies Nectandra leucantha, Nectandra rigida (Lauraceae) e Tapirira guianenesis (Anacardiaceae) por apresentarem placas de perfuração escalariforme com menos de 10 barras. As demais espécies mantiveram-se agrupadas, evidenciando um conjunto de características comuns como apresentado nas Tabelas 1 e 2.

A combinação dos resultados anatômicos sumarizados nas Tabelas 1 e 2 com a análise estatística sugere que as características ecológicas se sobrepõem às taxonômicas, e se justifica pela priorização, no presente trabalho, dos caracteres quantitativos. 

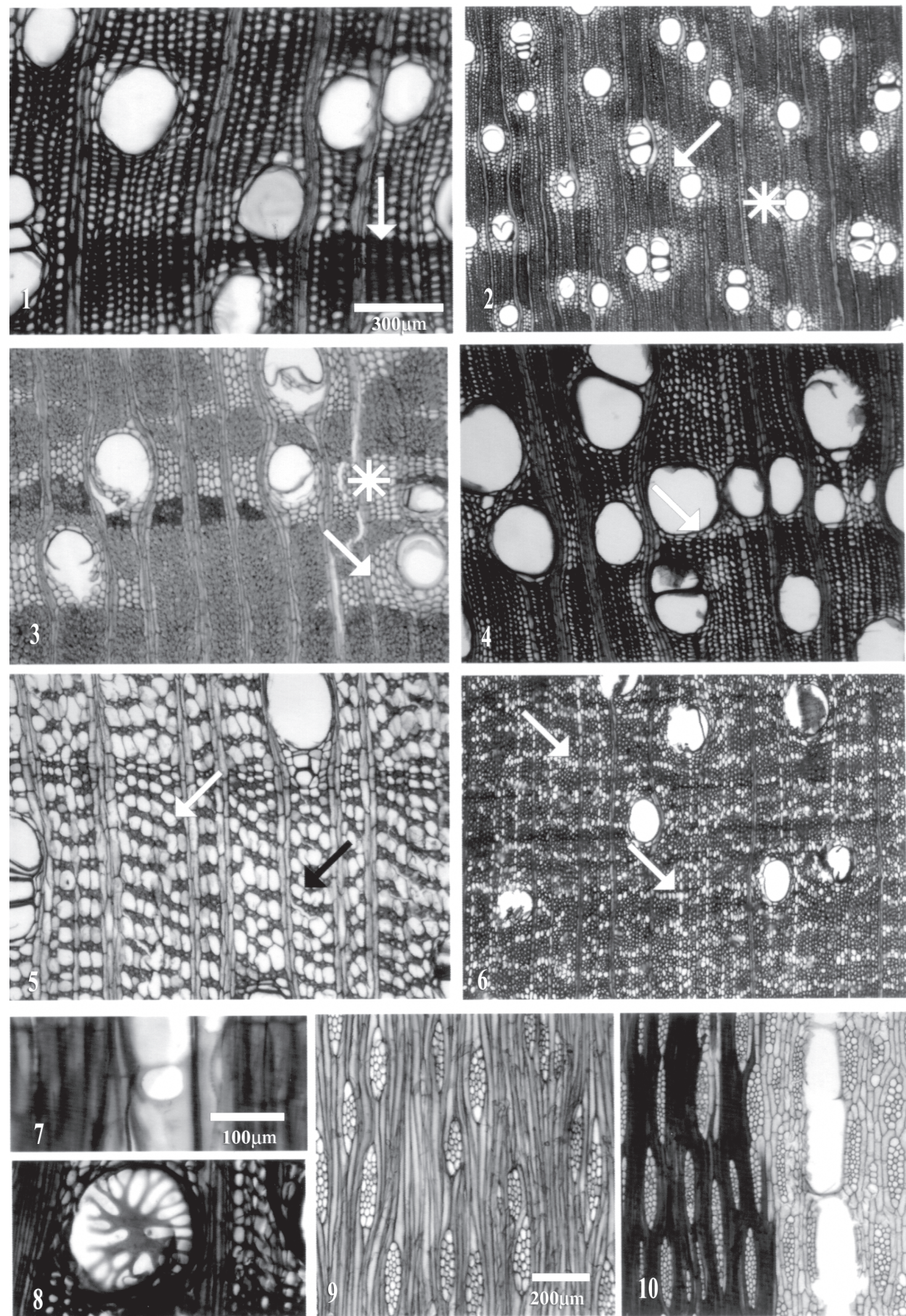

Figuras 1-10 - 1. Nectandra leucantha, seção transversal, evidenciando camada de crescimento distinta (seta). 2. Pseudopiptadenia contorta, seção transversal, evidenciando porosidade difusa e parênquima axial paratraqueal vasicêntrico (asterisco) e confluente (seta). 3. Andira fraxinifolia, seção transversal, nota-se parênquima axial paratraqueal aliforme (seta) e confluente (asterisco) . 4. Aegiphilla sellowiana, seção transversal evidenciando parênquima paratraqueal unilateral (seta). 5. Eriotheca pentaphylla, seção transversal, evidenciando parênquima axial em faixas (setas). 6. Calyptranthes langsdorfii, seção transversal, evidenciando parênquima apotraqueal difuso em agregados tendendo a formar linhas (setas). 7. Simira viridiflora, seção longitudinal radial evidenciando placa de perfuração simples. 8. Citharexylum myrianthum, seção transversal, observa-se placa de perfuração radiada. 9. Aegiphilla sellowiana seção longitudinal tangencial, observam-se os raios com 3 células de largura. 10. Eriotheca pentaphylla, seção longitudinal tangencial. 


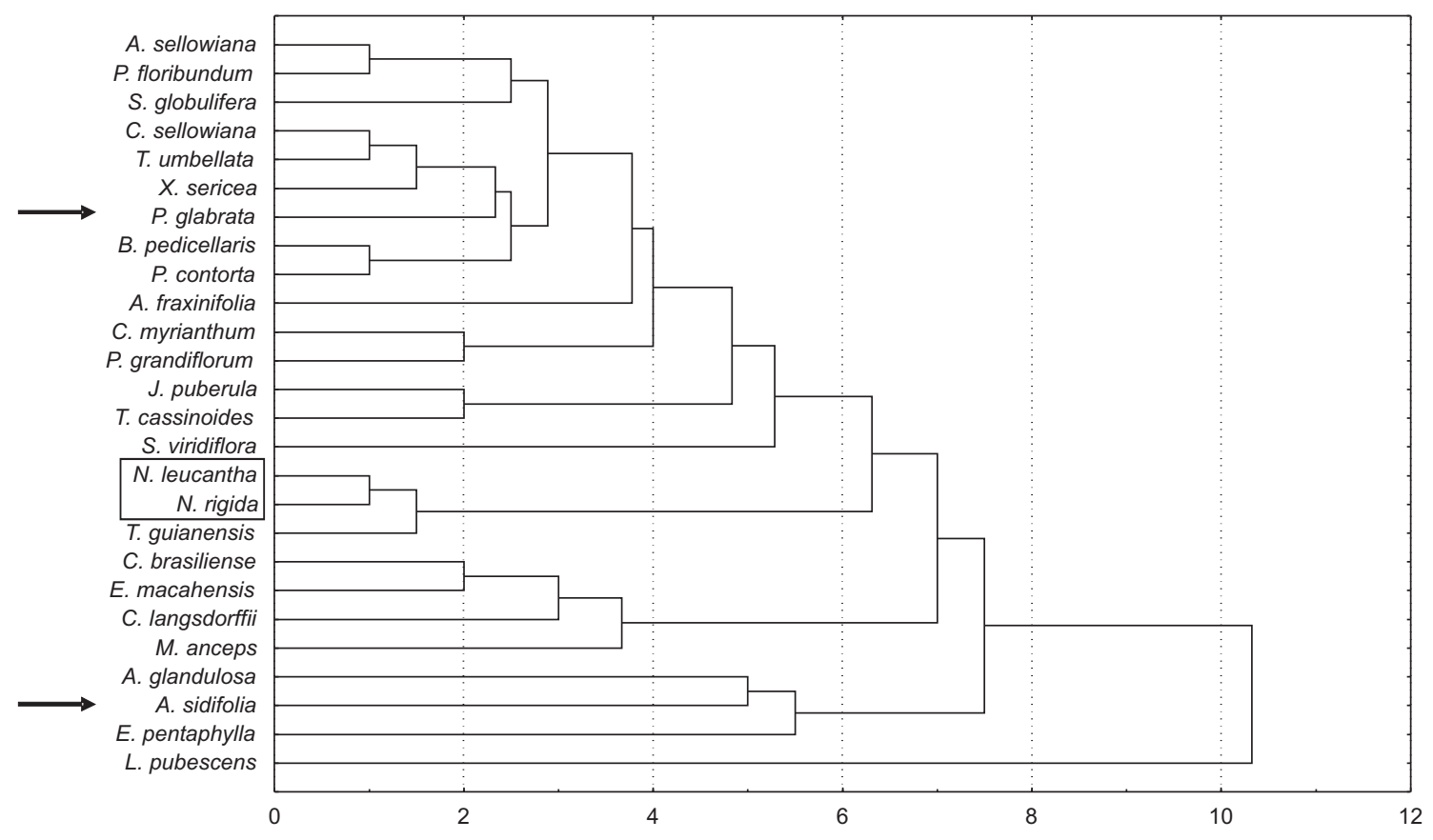

Figura 11 - Análise de agrupamento. O retângulo destaca as espécies de Lauraceae que se mantiveram próximas, enquanto as setas indicam as espécies de Euphorbiaceae.

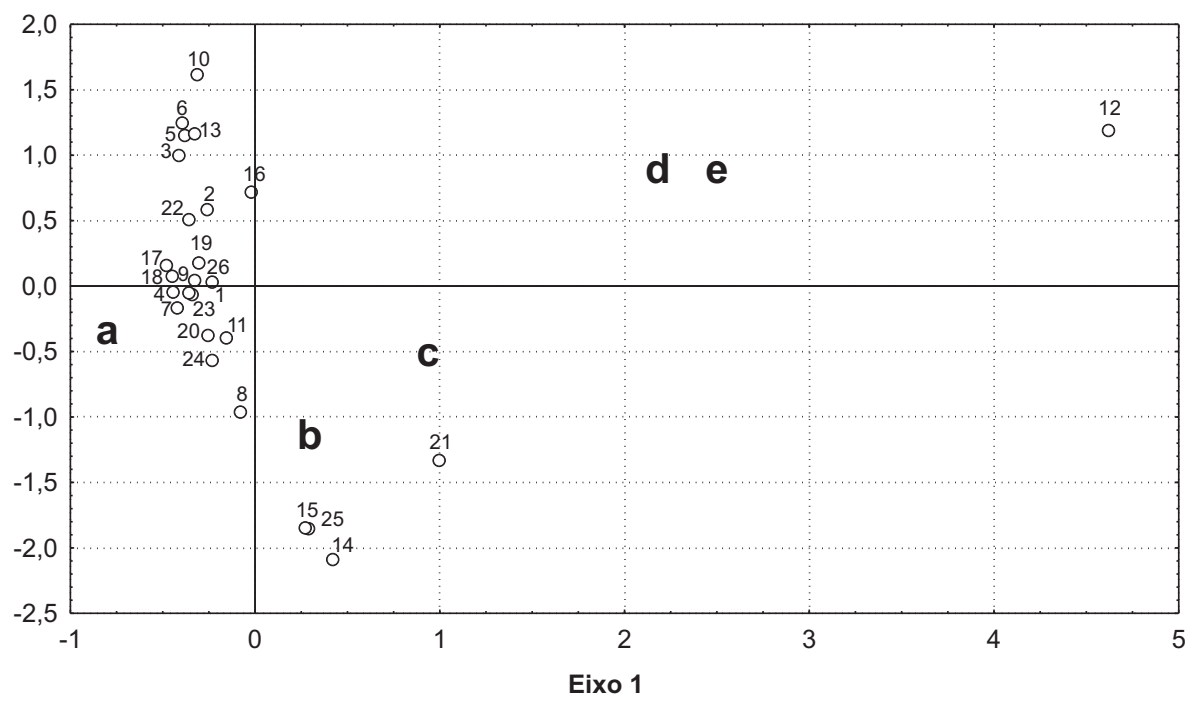

Figura 12 - Análise dos componentes principais. 1. Aegiphilla sellowiana, 2. Alchornea glandulosa, 3. Alchornea sidifolia, 4. Andira fraxinifolia, 5. Calyptranthes langsdorffii, 6. Calophyllum brasiliense, 7. Cordia sellowiana, 8. Cytharexylum myrianthum, 9. Eriotheca pentaphylla, 10. Eugenia macahensis, 11. Jacaranda puberula, 12. Lacistema pubescens, 13. Myrcia anceps 14. Nectandra leucantha, 15 - Nectandra rigida, 16. Pera glabrata, 17. Balizia pedicellaris, 18. Platymiscium floribundum, 19. Pseudobombax grandiflorum, 20. Pseudopiptadenia contorta, 21. Simira viridiflora, 22. Symphonia globulifera, 23. Tabebuia cassinoides, 24. Tabebuia umbellata, 25. Tapirira guianensis, 26. Xylopia sericea. a. placas de perfuração simples, b. placas de perfuração escalariformes $<10$ barras, c. vasos $/ \mathrm{mm}^{2}$, d. placas de perfuração escalariformes $>10$ barras, e. pontoações intervasculares opostas. 
Tabela 2 - Freqüência relativa das características anatômicas das espécies estudadas. Os diferentes tipos de placas de perfuração e parênquima axial podem ocorrer associados em uma mesma espécie, portanto a soma dos porcentuais ultrapassa $100 \%$.

\begin{tabular}{|c|c|}
\hline Características & Porcentagem \\
\hline Presença de anéis de crescimento & $96 \%$ \\
\hline Porosidade difusa & $96 \%$ \\
\hline Vasos exclusivamente solitários & $15 \%$ \\
\hline$<5$ vasos $/ \mathrm{mm}^{2}$ & $19 \%$ \\
\hline $5-20$ vasos $/ \mathrm{mm}^{2}$ & $73 \%$ \\
\hline $40-100$ vasos $/ \mathrm{mm}^{2}$ & $8 \%$ \\
\hline Diâmetro tangencial do elemento de vaso $<50 \mu \mathrm{m}$ & $8 \%$ \\
\hline Diâmetro tangencial do elemento de vaso entre 50 e $100 \mu \mathrm{m}$ & $23 \%$ \\
\hline Diâmetro tangencial do elemento de vaso entre 100 e $200 \mu \mathrm{m}$ & $65 \%$ \\
\hline Diâmetro tangencial do elemento de vaso $>200 \mu \mathrm{m}$ & $4 \%$ \\
\hline Comprimento do elemento de vaso $<350 \mu \mathrm{m}$ & $19 \%$ \\
\hline Comprimento do elemento de vaso entre 350 e $800 \mu \mathrm{m}$ & $65 \%$ \\
\hline Comprimento do elemento de vaso $>800 \mu \mathrm{m}$ & $15 \%$ \\
\hline Índice de agrupamento de vasos $<2$ & $81 \%$ \\
\hline Placas de perfuração simples & $96 \%$ \\
\hline Placas de perfuração escalariforme $<10$ barras & $12 \%$ \\
\hline Placas de perfuração escalariforme $>10$ barras & $4 \%$ \\
\hline Placas de perfuração radiadas & $4 \%$ \\
\hline Placas de perfuração foraminado-reticuladas & $4 \%$ \\
\hline Pontoações intervasculares opostas & $4 \%$ \\
\hline Pontoações intervasculares alternas & $81 \%$ \\
\hline Pontoações intervasculares diminutas $(<4 \mu \mathrm{m})$ & $12 \%$ \\
\hline Pontoações intervasculares pequenas (4 a $7 \mu \mathrm{m})$ & $27 \%$ \\
\hline Pontoações intervasculares médias (7 a $10 \mu \mathrm{m})$ & $31 \%$ \\
\hline Pontoações intervasculares grandes $(>10 \mu \mathrm{m})$ & $15 \%$ \\
\hline Pontoações intervasculares ornamentadas & $15 \%$ \\
\hline Pontoações raio-vasculares com aréolas distintas & $73 \%$ \\
\hline Pontoações raio-vasculares com aréolas reduzidas a simples & $27 \%$ \\
\hline Vasos com espessamento espiralado & $4 \%$ \\
\hline Traqueídes presentes & $19 \%$ \\
\hline Fibrotraqueídes & $31 \%$ \\
\hline Presença de fibras septadas & $27 \%$ \\
\hline Fibras com paredes delgadas & $12 \%$ \\
\hline Fibras com paredes delgadas a espessas & $81 \%$ \\
\hline Fibras com paredes espessas & $8 \%$ \\
\hline Fibras muito curtas $(<900 \mu \mathrm{m})$ & $4 \%$ \\
\hline Fibras curtas $(900$ a $1600 \mu \mathrm{m})$ & $73 \%$ \\
\hline Fibras longas $(>1600 \mu \mathrm{m})$ & $23 \%$ \\
\hline Parênquima axial raro & $4 \%$ \\
\hline Parênquima axial apotraqueal difuso & $15 \%$ \\
\hline Parênquima axial apotraqueal difuso em agregados & $23 \%$ \\
\hline Parênquima axial paratraqueal escasso & $19 \%$ \\
\hline Parênquima axial paratraqueal vasicêntrico & $46 \%$ \\
\hline
\end{tabular}




\begin{tabular}{lc}
\hline Características & Porcentagem \\
\hline Parênquima axial paratraqueal aliforme & $19 \%$ \\
Parênquima axial paratraqueal confluente & $38 \%$ \\
Parênquima axial paratraqueal unilateral & $12 \%$ \\
Parênquima axial em faixas > 3 células de largura & $27 \%$ \\
Parênquima axial em faixas de 1 a 3 células de largura & $12 \%$ \\
Parênquima axial reticulado & $4 \%$ \\
Parênquima axial marginal & $4 \%$ \\
Raios exclusivamente unisseriados & $12 \%$ \\
Raios de 1-3 células de largura & $85 \%$ \\
Raios > 4 células de largura & $35 \%$ \\
Raio > 1mm de altura & $8 \%$ \\
Presença de raios agregados & $31 \%$ \\
Raios apenas com células procumbentes & $31 \%$ \\
Raios apenas com células quadradas e/ou eretas & $12 \%$ \\
Raios com células procumbentes no corpo e 1 fileira de ereta e/ou & $62 \%$ \\
$\quad$ quadradas nas margens & \\
Raios com células procumbentes no corpo e 2 a 4 fileiras de ereta e/ou & $31 \%$ \\
$\quad$ quadradas nas margens & \\
Raios com células procumbentes, quadradas e eretas misturadas & $15 \%$ \\
4 a 12 raios/mm' & $85 \%$ \\
> 12 raios/mm' & $15 \%$ \\
Parênquima axial e/ou vasos estratificados & $8 \%$ \\
Raios e/ou elementos axiais irregularmente estratificados & $4 \%$ \\
Presença de cristais & $50 \%$ \\
\hline
\end{tabular}

\section{Discussão}

A estrutura anatômica do lenho das espécies analisadas neste trabalho foi descrita detalhadamente em Barros et al. (1997, 2001). Na presente abordagem, os seguintes caracteres apresentam incidência acima de 80\%: camadas de crescimento distintas, porosidade difusa, placas de perfuração simples, pontoações intervasculares alternas, índice de grupamento de vasos $<2$, fibras de paredes delgadas a espessas, freqüência de raios entre 4 e 12/mm' e raios com 1-3 células de largura. A alta incidência de características comuns foi corroborada pelas análises estatísticas, que mantiveram a maioria das espécies em um grupo único, o que sugere a existência de um padrão anatômico para a comunidade arbórea estudada. Este padrão se enquadra nas tendências ecológicas para espécies de terras baixas dos trópicos
(Dickison 1989; Wheeler \& Bass 1991), que tendem a apresentar menor freqüência de elementos de vaso mais largos e maior ocorrência de placas de perfuração simples. Entre as espécies estudadas, 69\% apresentam o diâmetro dos elementos de vaso maior que $100 \mu \mathrm{m}$; em $92 \%$ observam-se até 20 vasos $/ \mathrm{mm}^{2} ; 96 \%$ possuem placas de perfuração simples.

Carlquist (2001) comparou os dados da flora da Califórnia (Carlquist \& Hoekman 1985) com os de Metcalfe \& Chalk (1950) sobre a flora mundial e sugeriu que em regiões mais secas, características como maior freqüência de vasos e elementos de vaso finos e curtos são mais freqüentes. Estas adaptações proporcionam maior segurança ao transporte de água em plantas sujeitas a estresse. As mesmas características foram observadas por Carlquist (1977) em plantas 
do Ártico e de diferentes regiões da Austrália. Carlquist (2001) refere ainda que as espécies das florestas tropicais apresentam moderada seleção de características voltadas para a segurança na condução, priorizando adaptações que permitam o transporte de grandes volumes de água por unidade de tempo e por área transversal da madeira. Desta forma, as espécies de florestas tropicais devem apresentar características como menor freqüência de vasos e elementos de vaso mais largos e mais longos (Metcalfe \& Chalk 1950; Carlquist 1977, 2001). Os resultados do presente trabalho estão em conformidade com os dados da literatura que apontam a ocorrência freqüente dessas características nas flórulas tropicais, como verificado por Callado et al (1997) em um remanescente de Floresta Atlântica do estado do Rio de Janeiro e Baraja-Morales (1985) em dois remanescentes de floresta tropical do México.

A alta incidência de camadas de crescimento em espécies da Reserva Biológica de Poço das Antas, referida por Callado et al. (2001) é confirmada em 91\% das espécies aqui analisadas. Alves \& Angyalossy-Alfonso (2000) também observaram essa tendência em $48 \%$ das espécies brasileiras por elas estudadas. A despeito da alta freqüência de camadas de crescimento no lenho de espécies brasileiras, estudos sobre a periodicidade de formação dessas camadas são ainda escassos e mostram-se essenciais para o conhecimento das estratégias de sobrevivência dessas espécies, seu papel na fixação de $\mathrm{CO}_{2}$ e para estudos de dendrocronologia.

Dentre as espécies estudadas, 94\% apresentaram placas de perfuração simples, porcentual bastante semelhante ao observado por Alves \& Angyalossy-Alfonso (2000). Estes resultados estão em consonância com Baas (1976, 1986), Baas \& Schweingruber (1987) e Carlquist \& Hoekman (1985), que mencionam alta incidência de placas de perfuração simples em espécies de florestas tropicais de terras baixas. Carlquist (2001) considera que a mais importante alteração encontrada na anatomia da madeira de espécies de florestas tropicais úmidas é a elevada ocorrência de placas de perfuração simples, fator que reduz a fricção no transporte de água.

As análises estatísticas realizadas não indicaram correlação significativa entre as espécies analisadas e o tipo de parênquima axial. Porém, a Tabela 2 demonstra que apenas 3\% dessas espécies possuem parênquima escasso e aponta ainda uma grande diversidade de tipos de parênquima axial, com predominância do tipo paratraqueal. Alves \& Angyalossy-Alfonso (2002) observaram que em espécies brasileiras o parênquima axial é mais abundante em latitudes menores (até $23^{\circ}$ ), sendo o parênquima paratraqueal associado a climas mais quentes e o apotraqueal, a latitudes maiores e, conseqüentemente, a climas mais frios. Baas \& Zhang (1986), Baas et al. (1988) e Wheeler \& Baas (1991) referem que o parênquima axial é mais abundante nas regiões tropicais. Carlquist (2001), por sua vez, pondera que se o sistema condutor de água de espécies tropicais desenvolve características para transportar grandes volumes de água, os raios e o parênquima axial devem exibir mudanças similares.

As análises estatísticas realizadas e a Tabela 2 permitem concluir que as espécies analisadas apresentam características anatômicas próprias de regiões tropicais de terras baixas, que independem do grupo taxonômico a que as mesmas pertencem.

Outro ponto de destaque é a seleção de caracteres em famílias de ampla distribuição, aqui exemplificado com a família Lauraceae. Segundo Metcalfe \& Chalk (1950) e Richter (1987) alguns gêneros da famíla como Actinodaphne, Aiouea, Cinnamomum, Endlicheria, Laurus, Lindera, Persea, Phoebe, Plerothyrium e Sassafrás apresentam placas de perfuração 
simples e escalariforme associadas. O gênero Nectandra, segundo esses autores, apresenta apenas placas de perfuração escalariforme. Trabalhos recentes em regiões tropicais brasileiras (Barros et al. 1997, 2001; Oliveira et al. 2001; Oliveira 2005) têm demonstrado que é comum a ocorrência da associação de placas de perfuração simples e escalariforme, de poucas barras, em Nectandra, como observado no presente trabalho. Esta seleção de caracteres, que são próprios das famílias, mas que se enquadram nas tendências ecológicas postuladas por Dickson (1989) e Wheeler \& Baas (1991), provavelmente contribuem para os resultados encontrados e certamente auxiliam a compreensão da distribuição geográfica das espécies sob o ponto de vista da seleção de características importantes para a colonização de um dado bioma.

\section{Agradecimentos}

Os autores agradecem ao pesquisador Sebastião José da Silva Neto pelo auxílio na coleta dos indivíduos, além da valiosa colaboração no manuscrito, à técnica de laboratório Inês Cosme Neves Grillo, pela confecção das lâminas; ao CNPq, pela concessão de auxílio e bolsas de produtividade; à Petrobras, pelo patrocínio; à Fundação Botânica Margaret Mee, pela concessão de bolsa de apoio técnico e de nível superior, à UERJ/FAPERJ, pela concessão de bolsa PROCIÊNCIA e à FENORTE/ TECNORTE, pela concessão de auxílio.

\section{REFERÊNCIAS BIBLIOGRÁFICAS}

Alves, E. S. \& Angyalossy-Alfonso, V. 2000. Ecological trends in the wood anatomy of some Brazilian species. 1 . Growth rings and vessels. IAWA Journal 21(1): 3-30.

2002. Ecological trends in the wood anatomy of some Brazilian species. 2 . Axial parenchyma, rays and fibres. IAWA Journal 23(4): 391-418.
Baas, P. 1976. Some functional and adaptive aspects of vessel member morphology. Leiden Botanical Series. 3: 157-181. 1986. Ecological patterns in xylem anatomy. In: T. J. Givnish (ed.). On the economy of plant form and function. Cambridge University Press, Cambridge, New York. Pp. 327-352.

; Esser, P. M.; Van der Westen, M. E. T. \& Zandee, M. 1988. Wood anatomy of the Oleaceae. IAWA Bulletin n. s. 9:103-182.

\& Schweingruber, F. H. 1987. Ecological trends in the wood anatomy of trees, shrubs and climbers from Europe. IAWA Bulletin n.s. 8: 245-274.

\& Zhang, X. 1986. Wood anatomy of trees and shrubs from China. I. Oleaceae. IAWA Bulletin n.s. 7: 195-220.

; Werker, F. \& Fahn, A. 1983. Some ecological trends in vessel characters. IAWA Bulletin n. s. 4: 141-159.

Barajas-Morales, J. 1985. Wood structural differences between trees of two tropical forests in Mexico. IAWA Bulletin n. s. 6: 355-364.

Barros, C. F.; Callado, C. H.; Costa, C. G.; Pugialli, H. R. L.; Cunha, M. \& Marquete, O. 1997. Madeiras da Mata Atlântica-Anatomia do lenho de espécies ocorrentes nos remanescentes florestais do estado do Rio de Janeiro - Brasil. Volume I. Rio de Janeiro: Instituto de Pesquisas Jardim Botânico do Rio de Janeiro. 86p.

; Callado, C. H.; Marcon, M. L.; Costa, C. G.; Cunha, M.; Lima, H. R. P. \& Marquete, O. 2001. Madeiras da Mata Atlântica: anatomia do lenho de espécies ocorrentes nos remanescentes florestais do estado do Rio de Janeiro - Brasil. Volume II. Instituto de Pesquisas Jardim Botânico do Rio de Janeiro, Rio de Janeiro, 94p.

Bukatsch, F. 1972. Bemerkungen zur doppelfärbung astrablau-safranin. Mikrokosmos 61(8): 33-36. 
Callado, C. H.; Pugialli, H. R. P.; Costa, C. G.; Cunha, M.; Marquete, O.; Barros, C. F. 1997. Anatomia do lenho de espécies da Mata Atlântica: interpretação ecológica e indicações para aproveitamento. In: Lima, H. C. \& Guedes-Bruni, R. R. Serra de Macaé de Cima: diversidade florística e conservação em Mata Atlântica. Pp. 251-274.

Callado, C. H.; Silva Neto, S. J.; Scarano, F. R.; Barros, C. F. \& Costa, C. G. 2001. Anatomical features of growth rings in flood-prone trees of the Atlantic Rain Forest in Rio de Janeiro, Brazil. IAWA Journal 22(1): 29-42.

Carlquist, S. 1977. Ecological factors in wood evolution: a floristic approach. American Journal of Botany 64: 887-896.

.1984. Vessel grouping in dicotyledon woods: significance and relationship to imperforate tracheary elements. Aliso 10: 505-525.

2001. Comparative wood anatomy. Systematic, ecological and evolutionary aspects of dicotyledon wood. 2 ed.Springer-Verlag. 448p.

\& Hoekman, D. A. 1985. Ecological wood anatomy of the woody southern californian flora. IAWA Bulletin n.s. 6(4): 319-353.

Coradin, V. T. R. \& Muñiz, G. M. B. 1991. Normas de procedimentos em estudos de anatomia de madeira: I. Angiospermae. II. Gimnospermae. LPF, Brasilia, 19p.

Dickison, W. 1989. Steps toward the natural system of the dicotyledons: vegetative anatomy. Aliso 12(3): 555-566.

Guedes-Bruni, R. R. 1998. Composição, estrutura e similaridade florística de dossel em seis unidades fisionômicas da Mata Atlântica no Rio de Janeiro. Tese de Doutorado. Universidade de São Paulo, São Paulo. 231p.

Guedes-Bruni, R. R.; Morim, M. P.; Lima, H. C. \& Sylvestre, L. S. 2002. Inventário florístico. In: Sysvestre, L. S. \& Rosa, M.
M. T. Manual metodológico para estudos botânicos na Mata Atlântica. Seropédica, Edur. Pp. 24-50.

IAWA Committee. 1989. List of microscopic features for hardwood identification. IAWA Bulletin 10(2): 219-332.

Lima, H. C. 2000. Leguminosas arbóreas da Mata Atlântica - uma análise da riqueza, padrões de distribuição geográfica e similaridades florísticas em remanescentes florestais do estado do Rio de Janeiro. Tese de Doutorado. Universidade Federal do Rio de Janeiro, Rio de Janeiro, 156p.

Ludwig, J. A. \& Reynolds, J. F. 1988. Statistical Ecology. A primer on methods and computing. John Wiley \& Sons, New York, 368p.

Magurran, A. E. 1988. Ecological diversity and its measurement. Princeton University Press, Princeton. Pp. 81-99.

Marcati, C. R.; Angyalossy-Alfonso, V. \& Benetati, L. 2001. Anatomia comparada do lenho de Copaifera langsdorffii Desf. (Leguminosae-Caesalpinoideae) de floresta e cerradão. Revista Brasileira de Botânica 24(3): 311-320.

Metcalfe, C. R. \& Chalk, L. 1950. Anatomy of dicotyledons. Oxford University Press, London, 1500p.

Noshiro, S Suzuki, M. \& Ohba, H. 1995. Ecological wood anatomy of Nepalese Rhododendron (Ericaceae). 1. Interspecific variation. Journal of Plant Research 108: 1-9.

Nunes-Freitas, A. F. 2004. Bromeliáceas da Ilha Grande: variação inter-habitats na composição, riqueza e diversidade da comunidade. Tese de Doutorado. Universidade do Estado do Rio de Janeiro, Rio de Janeiro, 195p.

Oliveira, C. W. 2005. Anatomia da casca e do lenho de espécies de Nectandra Rol. ex Rottb. e Ocotea Aubl. (Lauraceae). Dissertação de Mestrado. Escola Nacional de Botânica Tropical, Instituto de Pesquisas Jardim Botânico do Rio de Janeiro, Rio de Janeiro. 
Oliveira, C. W.; Callado, C. H. \& Marquete, O. 2001. Anatomia do lenho de espécies do gênero Nectandra Rol. ex Rottb. (Lauraceae). Rodriguésia 52(81): 125-134.

Richter, H. G. 1987. Mature secondary xylem. In: Metcalfe, C. R. Anatomy of the dicotyledons. $2^{\text {nd }}$ ed., vol. III. Clarendon Press, Oxford. Pp. 162-168.

Sass, J. E. 1958. Elements of botanical microtechnique. McGraw-Hill Book Company Inc., New York-London, 222p.

Sneath, P. H. A. \& Sokal, R. R. 1973. Numerical taxonomy. W. H. Freeman \& Co., San Francisco.

Velloso, H. P.; Rangel Filho, A. L. R. \& Lima, J. C. A. 1992. Classificação da vegetação brasileira adaptada a um sistema universal. IBGE, Rio de Janeiro.

Vuono, Y. S. 2002. Inventário fitossociológico. In: Sysvestre, L. S. \& Rosa, M. M. T.
Manual metodológico para estudos botânicos na Mata Atlântica. Seropédica, Edur. Pp. 51-65.

Wheeler, E. A. \& Baas, P. 1991. A survey of the fossil record for dicotyledonous wood and its significance for evolutionary and ecological wood anatomy. IAWA Bulletin n. s. 12: 275-33.

Wiemann, M. C.; Wheeler, E. A.; Manchester, S. R. \& Portier, K. M. 1998. Dicotyledonous wood anatomical characters as predictors of climate. Paleogeography, Paleoclimatology, Paleoecology. 139: 83-100.

Woodcock, D. W.; Santos, G. \& Reynel, C. 2000. Wood characteristics of Amazon forest types. IAWA Journal 21(3): 277-292.

Zar, J. H. 1996. Biostatistical analysis. $3^{\text {rd }}$ ed. Prentice Hall, New Jersey. 